\title{
SUPERCRITICAL EXTRACTION OF LYOPHILIZED STRAWBERRY ANTHOCYANINS WITH PULSED ELECTRIC FIELDS PRETREATMENT
}

\author{
Marco A. Ávila-Hernández ${ }^{\text {a }}$, César Pérez-Alonso ${ }^{\text {a }}$ Juan Orozco-Villafuerte ${ }^{\mathrm{a}}$, Carlos E. Barrera-Díaz ${ }^{\mathrm{a}}$, Erik Alpizar-Reyes ${ }^{\mathrm{a}, \mathrm{b}}$ \\ and Julian Cruz-Olivares ${ }^{\mathrm{a}, \mathrm{c}, *, 1}$ \\ ${ }^{a}$ Facultad de Química. Universidad Autónoma del Estado de México. Paseo Colón esq. Paseo Tollocan S/N, 50120. Toluca, Estado \\ de México, México

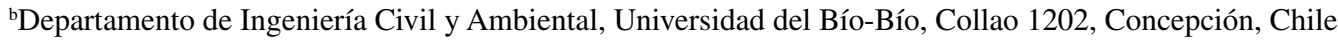 \\ ${ }^{\mathrm{c}}$ MCCM Ciencia e Innovación Tecnológica S.A. de C.V., Av. Benito Juárez Sur 1002, Col. Universidad, 50130, Toluca, Estado \\ de México, México
}

Recebido em 18/08/2021; aceito em 12/11/2021; publicado na web em 02/12/2021

\begin{abstract}
The lyophilized strawberry anthocyanins were extracted using a supercritical extraction (SE) process. The effect of pulsed electric fields (PEF) as pretreatment and the influence of the addition of ethanol as a cosolvent on the percentage of extraction yield (EY) and the total anthocyanin concentration (TAC) were analyzed. The effect of PEF was evaluated at 0.5 and $1.0 \mathrm{kV} / \mathrm{cm}$, while the effect of the cosolvent was studied in mixtures of supercritical carbon dioxide - ethanol $\left(\mathrm{SCCO}_{2}+\right.$ ethanol) at 1.6 and $3.3 \%$ by weight. The best results $\left(\% \mathrm{EY}=0.506, \mathrm{TAC}=0.428 \mathrm{~g} / 100 \mathrm{~g}\right.$ of lyophilized strawberry) were obtained with a PEF pretreatment of $1.0 \mathrm{kV} \mathrm{cm} \mathrm{c}^{-1}$, $3.3 \%$ wt. ethanol at 200 bar and $333.15 \mathrm{~K}$. The experimental results of solubility were suitably adjusted with the Kumar and Johnston model. The maximum solubility $(0.114 \mathrm{~g} / 100 \mathrm{~g}$ of solvent mixture) was obtained at 300 bar and $313.15 \mathrm{~K}$.
\end{abstract}

Keywords: lyophilized strawberry; anthocyanins; supercritical extraction; pulsed electric fields; supercritical carbon dioxide.

\section{INTRODUCTION}

Anthocyanins constitute the largest and probably the most important group of water-soluble plant pigments. ${ }^{1,2}$ These are responsible for the blue, purple, red and orange colour of many fruits and vegetables. ${ }^{3}$ Another important property is its antioxidant activity, which plays a vital role in the prevention of neuronal and cardiovascular diseases, as well as in cancer and diabetes, among other health beneficial effects of anthocyanins. ${ }^{4,5}$ Anthocyanins are used in the food industry due to their large number of biological properties and technological applications. They are used as antioxidants, natural colourants, preservatives, and components of smart packaging. ${ }^{4}$ In many cases, they are added to consumer products such as jams, jellies, and beverages to increase their antioxidant properties. ${ }^{6}$

The extract of strawberry (Fragaria ananassa) has been widely appreciated due to its high content of bioactive compounds, which show outstanding antioxidant abilities, ${ }^{7,8}$ also because of its flavour and fragrance that are widely used in industry. The anthocyanins in the strawberry are the most representative polyphenolic components. ${ }^{9}$ The main anthocyanins extracted from strawberries are delphinidin3-o-glucoside, cyanidin-3-o-glucoside, pelargonidin-3-o-glucoside, and malvidin-3-o-glucoside. ${ }^{10}$ Several studies report that the content of anthocyanins in strawberries ranges from 150 to $600 \mathrm{mg} \mathrm{kg}^{-1} .^{11,12}$ Pelargonidin-3-glucoside is the anthocyanin that has been found mostly in strawberries, in proportions ranging from 77 to $95 \%$ by weight of the anthocyanins present in the strawberry extracts. ${ }^{11,13}$

The extraction of anthocyanins from fruits is usually carried out by maceration using an acidified organic solvent. ${ }^{10}$ This process breaks down the cell membranes by dissolving and stabilizing the

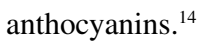

Alternatively, in recent years, other innovative methodologies such as ultrasound, microwave, pulsed light, pressurized liquid extraction, high hydrostatic pressure extraction, enzyme-assisted

\footnotetext{
*e-mail: jcruzo@uaemex.mx
}

extraction, and instantaneous controlled pressure drop-assisted extraction have been used. ${ }^{4,15}$ These technologies are implemented to improve extraction performance, increase extraction rate, operate at low temperatures, minimize loss from thermal degradation during processing, preserve the quality of extracted compounds, improve energy efficiency, and reduce the use of organic solvents. ${ }^{4}$

In accordance with the "Green Chemistry", another innovative and alternative technology that has been little used in industrial processes, but that has great potential to extract these types of compounds, is extraction with supercritical fluids. ${ }^{16,17}$ A supercritical fluid is a substance that is at temperature and pressure above its critical values $\left(\mathrm{T}_{\mathrm{c}}\right.$ and $\left.\mathrm{P}_{\mathrm{c}}\right)$. In supercritical extraction processes, an important parameter to develop applications of this technology is the solubility of the solute in the supercritical fluid. Solubility is usually analyzed experimentally in terms of the effects of pressure, temperature, and cosolvent. ${ }^{18}$

Supercritical fluids can diffuse through solids like a gas and dissolve materials like a liquid. ${ }^{19,20}$ Carbon dioxide $\left(\mathrm{CO}_{2}\right)$ is the most used supercritical fluid because it is safe, available and has a low cost, in addition to allowing supercritical operations at low pressures and near ambient temperatures, its critical point is $T_{c}=304.25 \mathrm{~K}$ and $\mathrm{P}_{\mathrm{c}}=73.8$ bar. ${ }^{21,22}$ Because the $\mathrm{CO}_{2}$ molecule is nonpolar, it does not have a net dipole moment, and therefore could only extract nonpolar substances. However, because $\mathrm{CO}_{2}$ has a quadruple moment, it can dissolve polar substances when used as a supercritical fluid at pressures up to $250 \mathrm{bar}^{23} \mathrm{In}$ this sense, the use of polar cosolvents such as water, ethanol or acetone in small proportions is recommended. ${ }^{24}$

When anthocyanins are extracted with supercritical fluids, it is pertinent to consider the operating conditions. Anthocyanins are more susceptible to pressure than to temperature since they are degraded at pressures above 1000 bar. ${ }^{25}$ Furthermore, the concentration of anthocyanins in the extract depends not only on the operating conditions but also on the pretreatment of the raw material and the percentage of cosolvent used in the mixture of $\mathrm{SCCO}_{2}$-Ethanol. ${ }^{26}$ According to Klopotek et al. ${ }^{27}$ in the case of the 
strawberry, the anthocyanins undergo degradation at temperatures close to $343.15 \mathrm{~K},{ }^{27,28}$ this same behaviour has been observed in the anthocyanins of other fruits such as grapes or raspberries. ${ }^{29}$

To try to minimize these adverse effects in the use of this technology, preliminary treatments to the raw material, such as ultrasound, microwave, infrared, among others have been proposed. ${ }^{30,31}$ It is important to note that the energy applied as a pretreatment does not affect the quality of the extract but improves the percentage of yield. ${ }^{32,33}$

Another form of pretreatment that has received great attention recently is applying pulsed electric fields (PEF). This novel technology consists of the intermittent application of high voltage $(\mathrm{kV})$ pulses for periods ranging from microseconds to milliseconds, through a material placed between 2 electrodes. ${ }^{34}$ This voltage generates an electric field whose intensity depends on the space between the electrodes and the voltage supplied. When the voltage is high enough, a phenomenon called electroporation occurs, which increases the permeability of the cytoplasmic membrane, improving the passage of ions and macromolecules through it. ${ }^{35,36}$ When electroporation is carried out in the membrane of a product from which it is intended to extract a component, the solvent or fluid used travels more easily and transports the component to be obtained more freely, this is the reason why PEF technology is used as a treatment before the extraction process. ${ }^{37,38}$

To generate electroporation in vegetable membranes such as strawberries, it is recommended to apply an electric potential of 0.2 to $1.0 \mathrm{kV} \mathrm{cm}^{-1}$ during periods of $10 \mathrm{~ms}$, to give a proper pretreatment to the sample without modifying its chemical components. ${ }^{39-41}$ The electrical potential is another factor that must be taken care of since the concentration of anthocyanins decreased when potentials greater than $1.2 \mathrm{kV} \mathrm{cm}^{-1}$ were applied. ${ }^{42}$

Therefore, the main objective of this work was to extract anthocyanins from lyophilized strawberry (LSB) pretreated with PEF using the supercritical fluid technique. For this, the objective was divided into the following activities: i) evaluate the effect of PEF pretreatment; ii) the use of ethanol as cosolvent on the extraction yield and total anthocyanins concentration and, iii) determine experimentally the solubility of the extract of strawberry.

\section{MATERIALS AND METHODS}

\section{Materials}

Fresh strawberries were purchased from regional producers who harvested this fruit from the municipality of Villa Guerrero, State of Mexico, Mexico (18 $58^{\prime}$ N-99 $\left.38^{\circ} \mathrm{W}\right)$. The carbon dioxide (99.99\%) was supplied by Infra México S.A. of C.V. (Toluca, State of Mexico, Mexico). The reagents methanol (99.8\%), ethanol (99.9\%), hydrochloric acid (37\%), potassium chloride (>99\%) and sodium acetate $(>99 \%)$ were purchased with the company Sigma-Aldrich S.A. of C.V. (Toluca, State of Mexico, Mexico).

\section{Strawberry lyophilization process}

The fresh strawberries were selected and washed with purified water at room temperature $\left(\sim 20^{\circ} \mathrm{C}\right)$ to remove impurities and dirt. The clean fruit was cut into slices approximately $0.4 \mathrm{~mm}$ thick. The drying process was carried out in 2 stages, ultra-freezing and lyophilization.

In the ultra-freezing, $600 \mathrm{~g}$ of the sliced samples were placed in 2 glass jars (Labconco 7540800) that were covered with aluminium foil. The vessels were deposited in an ultra-freezer (Thermo Scientific Revco EXF) operating at $-80^{\circ} \mathrm{C}$ for $24 \mathrm{~h}$. Next, in the lyophilization stage, the bottles with the frozen samples were placed in a lyophilizer (Labconco FreeZone) to extract the amount of water present in the samples through a vacuum pressure of 0.02 mbar at $-50{ }^{\circ} \mathrm{C}$ for $24 \mathrm{~h}$. The moisture of the samples was verified by weighing them on an analytical balance (Mettler Toledo AB204-S), at the end, the maximum amount of water in the lyophilized strawberry was $5 \%$ by weight. Finally, the lyophilized strawberry (LSB) was ground with a coffee mill (MrCoffee BVMC-BMH23/26) and sieved with a 20 mesh to homogenize their size.

\section{Extraction process of anthocyanins from lyophilized strawberry (LSB) with $\mathrm{SCCO}_{2}$ and selection of the best pressure and temperature conditions for the extraction process}

Two sets of experiments were carried out at 100 bar and 200 bar and three levels of temperature $(313.15,323.15$ and $333.15 \mathrm{~K})$ to define the pressure and temperature operating conditions for the extraction process of anthocyanins from LSB with $\mathrm{SCCO}_{2}$. The supercritical fluid extraction process was carried out according to the method proposed by Andrade-Avila et al., ${ }^{43}$ with slight modifications as shown in Figure 1. Briefly, a sample of $100 \mathrm{~g}$ of LSB was placed inside a stainless-steel high-pressure extraction cell. The cell was connected to a line of pipes and left inside the temperature conditioning chamber. $\mathrm{CO}_{2}$ contained in the tank was passed through the lines to displace the air in the pipes and the extraction cell. The flow rate of the $\mathrm{CO}_{2}$ fed into the extraction cell was $7.0 \mathrm{~mL} \mathrm{~min}{ }^{-1}$, for this purpose a high-pressure pump was used (Lab Alliance A19284). The feed went on until the desired experimental pressure of 100 or 200 bar was reached, which was obtained through a sensor (Honeywell GM) and pressure gauge. The temperature conditioning chamber has 2 heat sources with which the desired temperature $(313.15,323.15$ or $333.15 \mathrm{~K})$ was reached, which was recorded with a temperature-meter $\pm 1{ }^{\circ} \mathrm{C}$ (Honeywell DC). When the desired pressure and temperature were stable, the sample of LSB was left in contact with the $\mathrm{CO}_{2}$ inside the cell for $60 \mathrm{~min}$ to reach equilibrium. After the contact time had elapsed, the $\mathrm{CO}_{2}$ was released from the cell by opening a micrometric heating valve. At this stage of the process, the strawberry extract was carried by $\mathrm{CO}_{2}$ and collected in a cooled recovery cell. The flow rate in the separation step was $5.0 \mathrm{~mL} / \mathrm{min}$. The extract obtained was weighed on an analytical balance (Mettler Toledo AB204-S) for quantification. The schematic representation of the equipment used for this process is provided in a previous work. ${ }^{43}$ The extract obtained was kept in amber glass containers to avoid its degradation, before carrying out the following test.

Based on the results of these two sets of tests, the anthocyanins extracted from LSB at 200 bar and $313.15,323.15$ or $333.15 \mathrm{~K}$ did not present significant degradation, ${ }^{28}$ considering this characteristic as criterion for selecting the optimal operating conditions in the LSB extraction process.

\section{Supercritical extraction process of LSB}

Four procedures were developed to obtain anthocyanins from LSB with $\mathrm{SCCO}_{2}$ without cosolvent and with cosolvent, as well as with a pretreatment by PEF and without pretreatment. Table 1 describes the operating conditions of the procedures.

The procedure for the supercritical extraction process used in this section was the same described previously in section 2.3. Additionally, $100 \mathrm{~g}$ of LSB together with 12.5 or $25 \mathrm{~mL}$ of ethanol as cosolvent were placed into the extraction cell.

To carry out the PEF pretreatment, LSB was processed in batches of $100 \mathrm{~g}$ in a PEF device, which consists of a pulse generator (Makita EG4550A), which is connected to an oscilloscope (Owon Sds 1022). 


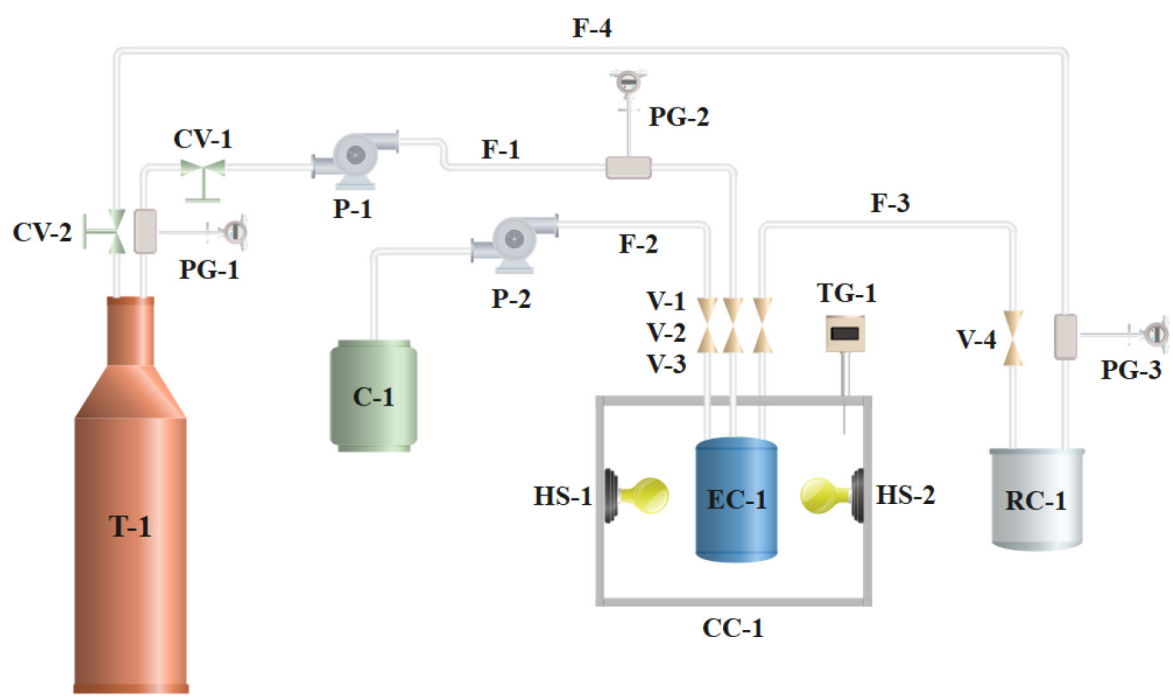

Figure 1. Apparatus of the supercritical extraction process. T1, $\mathrm{CO}_{2}$ Tank; C1, Cosolvent container; CC1, Conditioning chamber; EC1, Extraction cell; CV1 and CV2 Control valves; HS1 and HS2 Heat sources; P1 and P1 Pumps; PG1 to PG3 Pressure gauges; RC1 Recovery cell; TG1 Temperature gauge; V1 to V4 Valves; $\mathrm{F} 1, \mathrm{CO}_{2}$ feed; $\mathrm{F} 2$ Cosolvent; $\mathrm{F} 3$ Anthocyanins extract; $\mathrm{F} 4, \mathrm{CO}_{2}$ recovered

Table 1. Experimental conditions for the supercritical extraction process

\begin{tabular}{|c|c|c|c|}
\hline Code & Supercritical extraction process & Cosolvent & Pretreatment by PEF \\
\hline 1 & 200 bar at $313.15,323.15$ and $333.15 \mathrm{~K}$. & ------- & --------- \\
\hline 2 & 200 bar at $313.15,323.15$ and $333.15 \mathrm{~K}$. & -------- & 3 pulses of $10 \mu$ s with electrical potentials of 0.5 and $1.0 \mathrm{kV} / \mathrm{cm}$ \\
\hline 3 & 200 bar at $313.15,323.15$ and $333.15 \mathrm{~K}$. & 12.5 or $25 \mathrm{~mL}$ of ethanol & -------- \\
\hline 4 & 200 bar at $313.15,323.15$ and $333.15 \mathrm{~K}$. & $25 \mathrm{~mL}$ of ethanol & 3 pulses of $10 \mu$ s with an electrical potential of $1.0 \mathrm{kV} / \mathrm{cm}$ \\
\hline
\end{tabular}

The treatment chamber is connected to the generator employing 2 stainless steel electrodes. The control of the operating conditions was carried out through computer equipment, which is in contact with the oscilloscope and the pulse generator. To each of the samples was applied 3 pulses of $10 \mu$ s with electrical potentials of 0.5 and $1.0 \mathrm{kV} / \mathrm{cm}^{34,39}$

\section{Process of solubility determination}

Based on the procedure described in subsection 2.3, twelve experiments were carried out, in each of them, $100 \mathrm{~g}$ of LSB pretreated with $1.0 \mathrm{kV} \mathrm{cm}^{-1}$ of PEF together $25 \mathrm{~mL}$ (19.725 g) of ethanol were placed into the extraction cell.

The pressure and temperature conditions reached inside the extraction cell were 150, 200, 250 and 300 bar at 313.15, 323.15 and $333.15 \mathrm{~K}$. After one hour of contact time, the amount of extract obtained was stored in amber glass containers and weighed. The amount of $\mathrm{CO}_{2}$ used in each experiment was calculated with the feed flow. The experimental solubility was calculated as the amount in grams of extract obtained per $100 \mathrm{~g}$ of $\mathrm{CO}_{2}$.

The experimental data were analyzed using the Kumar and Johnston model, ${ }^{44}$ which is expressed by equation 1 . The model adjustment parameters were obtained by non-linear regression using Polymath 6.0 software.

$$
\operatorname{LnS}=A-\frac{B}{T}+C \times \rho_{C O 2}
$$

where $S$ is the solubility in $\mathrm{g}$ of extract/100 $\mathrm{g}$ of $\mathrm{CO}_{2}, T$ is the temperature in $\mathrm{K}$ and denotes the density of $\mathrm{CO}_{2}$ in $\mathrm{g} \mathrm{mL}^{-145}$ and the adjustable parameters $A, B$ and $C$ are constants determined by fitting the correlation to experimental data.

\section{Percentage of extraction yield in the supercritical extraction} process

The percentage of extraction yield (\% EY) was obtained using the following equation:

$$
\text { Extraction Yield }(w t \%)=\frac{\text { extract weigth }(g)}{100 g \text { of } L S B} \times 100
$$

\section{Determination of total anthocyanins concentration (TAC)}

TAC was determined according to the differential $\mathrm{pH}$ methodology described by Pérez-Orozco et al., ${ }^{1}$ and Babova et al. ${ }^{18}$ Two buffer solutions were prepared, the first one of $0.025 \mathrm{~mol} \mathrm{~L}^{-1} / \mathrm{HCl}$ potassium chloride with $\mathrm{pH}=1$, the second one was a $0.4 \mathrm{~mol} \mathrm{~L}^{-1}$ sodium acetate/ $\mathrm{HCl}$ solution with $\mathrm{pH}=4.5$, both solutions were measured with a potentiometer (Conductronic $\mathrm{pH} 120$ ). Subsequently, solutions of the obtained extracts were prepared to determine the dilution factor to be used, for this, a sample of each extraction was taken and dissolved in $10 \mathrm{~mL}$ of the $0.025 \mathrm{~mol} \mathrm{~L}^{-1} / \mathrm{HCl}$ potassium chloride solution. The amount of extract used to prepare this solution was determined considering that the measured absorbance was less than 1.2.

With the dilution factor obtained, two samples of each extract were taken, and solutions were prepared with the potassium chloride and sodium acetate buffers. Of each solution obtained, two absorbances were measured in a UV-Vis spectrophotometer (Thermo Scientific UV-Vis 10), one at $496 \mathrm{~nm}$ and the other at $700 \mathrm{~nm}$. The calculation of absorbances and total anthocyanins were obtained by equations (3) and (4),

$$
A=\left(A_{496}-A_{700}\right)_{p H 1.0}-\left(A_{496}-A_{700}\right)_{p H 4.5}
$$


where $A$ is the total absorbance, $\mathrm{A}_{496}$ is the absorbance measured at $496 \mathrm{~nm}$ and $\mathrm{A}_{700}$ is the absorbance measured at $700 \mathrm{~nm}$,

$$
T A C=\frac{(A)(M W)(D F)(1000)}{(\varepsilon)}
$$

where $T A C$ is in $(\mathrm{mg} / \mathrm{L}), A$ is the total absorbance, $M W$ is the molecular weight of the anthocyanin (for the pelargonidin 3-glucoside is $\left.433 \mathrm{~g} \mathrm{~mol}^{-1}\right), D F$ is the dilution factor (per example, if a sample of $0.2 \mathrm{~mL}$ is diluted in $3 \mathrm{~mL}, \mathrm{DF}=15$ ) and $\varepsilon$ is the molar absorptivity (for the pelargonidin 3-glucoside it is $15600 \mathrm{~L} / \mathrm{mol}-\mathrm{cm}$ ).

\section{Statistical analysis}

Data were analyzed using a one-way analysis of variance (ANOVA) and a Tukey's test for a statistical significance $\mathrm{P} \leq 0.05$, using the software Minitab 17. All experiments were done by duplicate.

\section{RESULTS AND DISCUSSION}

\section{Preliminary analysis for the selection of the best pressure and temperature conditions for the extraction process with supercritical $\mathrm{CO}_{2}$}

The results of $\% \mathrm{EY}$ and TAC obtained in the preliminary tests, where pure $\mathrm{CO}_{2}$ was used as extraction fluid, show that $\% \mathrm{EY}$ values at 200 bar are $0.185,0.218$ and 0.284 at $313.15,323.15$ and $333.15 \mathrm{~K}$ respectively. These values are on average $40.4 \%$ higher than those obtained at 100 bar. Concerning the TAC values, at 200 bar and these same temperatures, the results were $29.7 \%$ higher than those obtained at 100 bar.

This increase is basically since when the pressure increases at constant temperature, the density of the $\mathrm{SCCO}_{2}$ also increases and therefore its extracting capacity. ${ }^{21,45}$ Therefore, the best extraction conditions for supercritical fluids were 200 bar and those temperatures.

\section{Supercritical extraction process of LSB without PEF pretreatment and without cosolvent}

As can be seen in Table 2, both the \%EY and the TAC increase with the increase in temperature, obtaining the highest values of $\% \mathrm{EY}(0.284 \%)$ and TAC $(0.231 \mathrm{~g} / 100 \mathrm{~g} \mathrm{LSB})$ at $333.15 \mathrm{~K}$ and
200 bar (experiment 6). These results were obtained in a supercritical extraction process using pure $\mathrm{CO}_{2}$ and were taken as a reference to evaluate the effects of PEF and ethanol in experiments 7 to 11 . These results can be explained by the fact that when the temperature increases, although the density of the solvent decreases, the vapour pressure of the solute increases. Therefore, the effect of the increase in the vapour pressure of the solute is greater than that of the reduction in the density of the solvent, obtaining greater amounts of anthocyanins. ${ }^{46}$ In this case, this effect is evident since the \% EY and TAC increases considerably concerning the values obtained at lower temperatures. Using $\mathrm{SCCO}_{2}$ at the same pressure and temperature conditions, Sato et al.,${ }^{24}$ reported an extraction percentage of 0.26 . Regarding the total anthocyanin content, it is within the range reported by Lopes da Silva et al. ${ }^{11}$

\section{Supercritical extraction process of LSB with PEF pretreatment and without cosolvent}

The individual effect of PEF can be seen in experiments 7 and 8 in Table 2, with a PEF pretreatment of 0.5 and $1.0 \mathrm{kV} / \mathrm{cm}$, the results of $\% \mathrm{EY}$ were 0.298 and 0.356 , these results are $4.9 \%$ and $25.4 \%$ larger than those obtained without PEF pretreatment, respectively. For the TAC results, the behaviour is similar. In this case, the values increased 6.9 and $29 \%$ when PEF pretreatments of 0.5 and $1 \mathrm{kV} \mathrm{cm}^{-1}$ were applied, respectively. This behaviour has already been observed in another kind of fruit, for example, in the process of grape component extraction, it was reached up to $88 \%$ more extract when applying this pretreatment. ${ }^{47}$ These results can be explained based on the electroporation phenomenon generated by the PEF. By applying the electric pulse, the structure of the plant matrix is modified, which causes an increase in the size of the pores and therefore, the extraction process is easier, and the yields are substantially increased. ${ }^{48}$

\section{Supercritical extraction process of LSB without PEF pretreatment and with cosolvent}

The individual effect of ethanol as a cosolvent is also positive. Because both the \% EY and the TAC increase when a greater amount of cosolvent is added. When comparing the results of $\% \mathrm{EY}$ and TAC with those obtained without the use of cosolvent (experiment 6 , Table 2). When adding $12.5 \mathrm{~mL}(9.863 \mathrm{~g})$ of ethanol, the increase in $\% \mathrm{EY}$ was $27.5 \%$ and $32 \%$ when $25 \mathrm{~mL}$ (19.725 g) of ethanol were added as a cosolvent. In the same way, the TAC results increased $32 \%$

Table 2. Results of \%EY and TAC at different conditions of T, PEF and amount of ethanol

\begin{tabular}{|c|c|c|c|c|c|c|c|c|}
\hline Experiment & $\begin{array}{l}\text { LSB } \\
(\mathrm{g})\end{array}$ & $\begin{array}{c}\text { PEF } \\
(\mathrm{kV} / \mathrm{cm})\end{array}$ & $\begin{array}{c}\text { Ethanol } \\
(\mathrm{g})\end{array}$ & $\begin{array}{c}\mathrm{SC}-\mathrm{CO}_{2} \\
(\mathrm{~g})\end{array}$ & $\begin{array}{c}\text { Pressure } \\
\text { (bar) }\end{array}$ & $\begin{array}{c}\text { Temperature } \\
(\mathrm{K})\end{array}$ & $\begin{array}{l}* \mathrm{EY} \\
(\%)\end{array}$ & *TAC $(\mathrm{g} / 100 \mathrm{~g}$ of LSB) \\
\hline 1 & 100 & 0 & 0 & 515.448 & 100 & 313.15 & 0.13 & 0.112 \\
\hline 2 & 100 & 0 & 0 & 315.151 & 100 & 323.15 & 0.16 & 0.143 \\
\hline 3 & 100 & 0 & 0 & 237.720 & 100 & 333.15 & 0.21 & 0.185 \\
\hline 4 & 100 & 0 & 0 & 688.635 & 200 & 313.15 & 0.19 & 0.158 \\
\hline 5 & 100 & 0 & 0 & 643.128 & 200 & 323.15 & 0.22 & 0.176 \\
\hline 6 & 100 & 0 & 0 & 593.434 & 200 & 333.15 & 0.28 & 0.231 \\
\hline 7 & 100 & 0.5 & 0 & 593.434 & 200 & 333.15 & 0.30 & 0.247 \\
\hline 8 & 100 & 1 & 0 & 593.434 & 200 & 333.15 & 0.36 & 0.298 \\
\hline 9 & 100 & 0 & 9.863 & 584.388 & 200 & 333.15 & 0.36 & 0.305 \\
\hline 10 & 100 & 0 & 19.725 & 575.342 & 200 & 333.15 & 0.38 & 0.315 \\
\hline 11 & 100 & 1 & 19.725 & 575.342 & 200 & 333.15 & 0.51 & 0.428 \\
\hline
\end{tabular}

*Average values of two runs with a standard deviation of 0.02 on average. According to the Tukey test, there are no significant differences between the means of the treatments. 
and $36.4 \%$ with the same amounts of added ethanol. In these results, the function of the cosolvent is observed by increasing the polarity and the solvent strength, which favours the solubility and selectivity of more polar compounds that strawberries contain. ${ }^{49}$

\section{Supercritical extraction process of LSB with PEF pretreatment and with cosolvent}

It is worth saying that the combined effect of $1.0 \mathrm{kV} \mathrm{cm}^{-1}$ and $25 \mathrm{~mL}(19.725 \mathrm{~g})$ of ethanol produced an increase of $78.2 \%$ for the EY and $85.3 \%$ for the TAC. These results suggest that there is a synergistic effect. Both the electroporation caused by PEF in the LSB and the increase in polarity due to the addition of ethanol produce a substantial improvement over \%EY and TAC. It is reported that the effect of ethanol as a cosolvent improved the total amount of saccharides extracted from strawberries by $72 \%$, concerning the value obtained using only pure $\mathrm{SCCO}_{2} \cdot{ }^{24}$ However, no supercritical anthocyanin extraction results were found specifically from lyophilized strawberries and with PEF pretreatment.

\section{Solubility determination}

Based on the results of Table 2, for the study of the solubility of the strawberry extract in the ethanol $+\mathrm{SCCO}_{2}$ mixture, twelve experiments were carried out with $100 \mathrm{~g}$ of LSB, with pretreatment of $1.0 \mathrm{kV} \mathrm{cm}^{-1}$ and using $25 \mathrm{~mL}(19.725 \mathrm{~g})$ of ethanol as a cosolvent. Results are shown in Figures 2 and 3. As can be seen, the effects of temperature and pressure on \%EY, TAC and Solubility $(S)$ are always positive. In this case, the retrograde solubility behaviour is not present, which is more common in solid-fluid systems with solutes and pure supercritical fluids. ${ }^{45,49}$

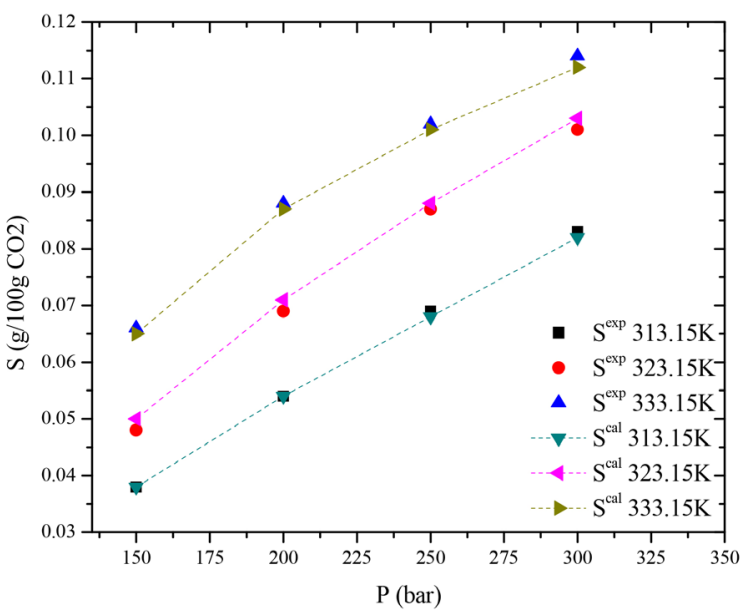

Figure 2. Effect of pressure on solubility for $\mathrm{LSB}$ in $\mathrm{SCCO}_{2}$ at different temperatures

In general terms, the effect of pressure is greater than the effect of temperature. For every 50 bar increase in pressure from 150 to 300 bar, regardless of temperature, the average increase in \% EY, TAC and $S$ was $36 \%, 38 \%$ and $26 \%$ respectively. While the increase in $\% \mathrm{EY}, \mathrm{TAC}$ and $S$ was $15 \%, 15 \%$ and $24 \%$ respectively, for every $10 \mathrm{~K}$ increase in temperature. These results are attributed to the increased solvation power of $\mathrm{CO}_{2}$ because of density, since, when the pressure increases, the density of the supercritical fluid increases considerably, therefore, the distance between its molecules decreases and a better interaction is achieved. Additionally, the effect of pressure on the solute causes ruptures in the matrix of the plant sample, facilitating the release of the solute and consequently improving both solubility

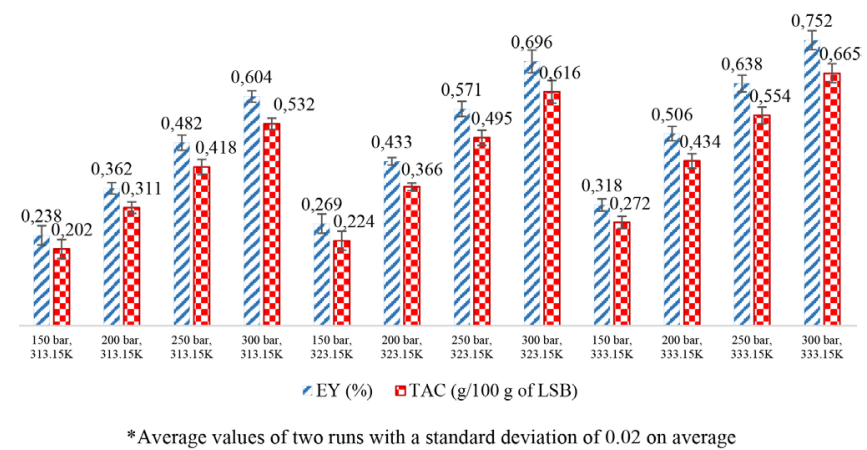

Figure 3. Results of $E Y(\%)$ and TAC at different conditions of $P$ and $T$ from $100 \mathrm{~g}$ of $\mathrm{LSB}$ with $1.0 \mathrm{kV} / \mathrm{cm}$ of PEF pretreatment in Ethanol- $\mathrm{SCCO}_{2}$

and mass transfer rates. Similar results were found by Sato et al., ${ }^{24}$ who analyzed the percentage of saccharides and the antioxidant effect of strawberry extracts under different conditions of $\mathrm{P}, \mathrm{T}$ and solvents. They report that the extraction yield increases slightly with an increase in pressure above 200 bar, while it remains practically constant because of temperature.

The experimental data were analyzed using the Kumar and Johnston model. ${ }^{44}$ They were successfully correlated with this model, in terms of the coefficient of determination $\left(r^{2}>0.99\right)$ and average absolute relative deviation (AARD $<2.83 \%$ ), see Table 3 .

Table 3. Parameters of the Kumar and Johnston model

\begin{tabular}{ccccc}
\hline $\mathrm{T}(\mathrm{K})$ & $\mathrm{A}$ & $\mathrm{B}$ & $\mathrm{C}$ & $\mathrm{r}^{2}$ \\
\hline 313.15 & 54.848 & 19665 & 5.9858 & 0.998 \\
323.15 & 54.848 & 19665 & 4.2918 & 0.996 \\
333.15 & 54.848 & 19665 & 2.3974 & 0.997 \\
\hline
\end{tabular}

As mentioned previously, the effect of temperature and pressure on the solubility of the strawberry extract is positive in both cases, however, the effect of pressure is more perceptible than the effect of temperature. As the pressure rises at a constant temperature, the $\mathrm{CO}_{2}$ density also increases, thus decreasing the intermolecular space between $\mathrm{CO}_{2}$ molecules, therefore, increases the interactions between anthocyanins and $\mathrm{CO}_{2}$ molecules, causing solubility to increase with pressure. This is since the density of $\mathrm{SCCO}_{2}$ is more sensitive to this variable. Another factor that affects the solubility of anthocyanins is the temperature of the system, which influences the vapour pressure of the solute, the density of the solvent and the intermolecular interactions in the fluid phase. Therefore, the solubility results at $333.15 \mathrm{~K}$ are greater than at lower temperatures due to the high interactions of anthocyanin and $\mathrm{CO}_{2}+$ Ethanol fluid. ${ }^{50}$

\section{CONCLUSIONS}

Anthocyanins from LSB and with a PEF pretreatment were extracted with ethanol $+\mathrm{SCCO}_{2}$. The extraction at 200 bar, 333.15, $3.3 \%$ wt. of ethanol as cosolvent and using LSB with a PEF pretreatment of $1 \mathrm{kV} / \mathrm{cm}$, produced an extraction yield of $0.284 \%$ and a TAC of $0.231\left(\mathrm{~g} / 100 \mathrm{~g}\right.$ of ethanol $\left.+\mathrm{SCCO}_{2}\right)$. The individual effect of $1.0 \mathrm{kV} / \mathrm{cm}$ of PEF pretreatment increases the \%EY by $25 \%$ and the TAC by $29 \%$. The individual effect of the cosolvent increases the $\% \mathrm{EY}$ by $32 \%$ and that of TAC by $36.4 \%$. However, the combined effect of $1.0 \mathrm{kV} \mathrm{cm}^{-1}$ and $3.3 \%$ ethanol, produced an increase of $78.2 \%$ and $85.3 \%$ in the $\% \mathrm{EY}$ and TAC, respectively. Therefore, these results suggest that there is a synergistic effect, which means that both the electroporation caused by PEF in the LSB and the increase in polarity due to the addition of ethanol produce 
a substantial improvement over \%ET and TAC. Furthermore, the process of extracting anthocyanins from LSB using a mixture of ethanol + supercritical carbon dioxide can be satisfactorily described by a solubility-based model such as the Kumar and Johnston model.

\section{ACKNOWLEDGMENTS}

The authors would like to thank the National Council of Science and Technology of Mexico (CONACyT) for the scholarship granted to the master's student in chemical sciences Marco A. Ávila-Hernández.

\section{REFERENCES}

1. Pérez-Orozco, J. P.; Sánchez-Herrera, L. M.; Ortiz-Basurto, R. I.; Food Hydrocolloids 2019, 87, 297.

2. Smeriglio, A.; Barreca, D.; Bellocco, E.; Trombetta, D.; Phytother Res. 2016, 30, 1265.

3. de Pascual-Teresa, S.; Sanchez-Ballesta, M. T.; Phytochem. Rev. 2007, 7,281.

4. Arruda, H. S.; Silva, E. K.; Araujo, N. M. P.; Pereira, G. A.; Pastore, G. M.; Junior, M. R. M.; Molecules 2021, 26, 2632.

5. Lazăr, N.-N. C.; Croitoru, C.; Enachi, E.; Bahrim, G.-E.; Stănciuc, N.; Râpeanu, G.; Plants 2021, 10, 577.

6. Bolotov, V. M.; Savvin, P. N.; Komarova, E. V; Koshevarova, I. B.; IOP Conf. Ser. Earth Environ. Sci. 2021, 640, 052001.

7. Van de Velde, F.; Esposito, D.; Grace, M. H.; Pirovani, M. E.; Lila, M. A.; Food Res. Int. 2019, 121, 453.

8. Romandini, S.; Mazzoni, L.; Giampieri, F.; Tulipani, S.; Gasparrini, M.; Forbes-Hernandez, T. Y.; Locorotondo, N.; D'Alessandro, M.; Mezzetti, B.; Bompadre, S.; Alvarez-Suarez, J. M.; J. Berry Res. 2013, 3, 169.

9. Kjersti, A.; Grete, S.; Wrolstad, R. E.; J. Agric. Food Chem. 2005, 53, 4032 .

10. Karaaslan, N. M.; Yaman, M.; Int. J. Food Prop. 2017, 20, 2313.

11. da Silva, F. L.; Escribano-Bailón, M. T.; Pérez Alonso, J. J.; RivasGonzalo, J. C.; Santos-Buelga, C.; LWT - Food Sci. Technol. 2007, 40, 374.

12. Clifford, M. N.; J. Sci. Food Agric. 2000, 80, 1063.

13. Lopes-da-Silva, F.; de Pascual-Teresa, S.; Rivas-Gonzalo, J.; SantosBuelga, C.; Eur. Food Res. Technol. 2001, 214, 248.

14. Naczk, M.; Shahidi, F.; J. Chromatogr. A 2004, 1054, 95.

15. Soquetta, M. B.; Terra, L. de M.; Bastos, C. P.; CYTA J. Food 2018, 16, 400.

16. Sánchez-Mesa, N.; Sepúlveda-Valencia, J. U.; Ciro-Velásquez, H. J.; Meireles, M. A.; Rev. Mex. Ing. Química 2020, 19, 755.

17. Chemat, F.; Vian, M. A.; Cravotto, G.; Int. J. Mol. Sci. 2012, 13, 8615.

18. Babova, O.; Occhipinti, A.; Capuzzo, A.; Maffei, M. E.; J. Supercrit. Fluids 2016, 107, 358 .

19. Brunner, G.; J. Food Eng. 2005, 67, 21.

20. Eckert, C. A.; Knutson, B. L.; Debenedetti, P. G.; Nature 1996, 383, 313

21. Alexandre, A. M. R. C.; Matias, A.; Duarte, C. M. M.; Bronze, M. R.; J. CO2 Util. 2018, 27, 73 .

22. Ortiz-Estrada, C. H.; Díaz-Díaz, C. Y.; Cruz-Olivares, J.; Pérez-Alonso, C.; Rev. Mex. Ing. Química 2015, 14, 49.

23. Maity, S.; Mukhopadhyay, P.; Kundu, P. P.; Chakraborti, A. S.; Carbohydr. Polym. 2017, 170, 124.
24. Sato, T.; Fukuda, F.; Nihei, K. ichi; Itoh, N.; J. Supercrit. Fluids 2017, $130,23$.

25. Marszałek, K.; Woźniak, Ł.; Kruszewski, B.; Skąpska, S.; Int. J. Mol. Sci. 2017, 18, 277.

26. Pereira, P. H. F.; Oliveira, T. Í. S.; Rosa, M. F.; Cavalcante, F. L.; Moates, G. K.; Wellner, N.; Waldron, K. W.; Azeredo, H. M. C.; Int. J. Biol. Macromol. 2016, 88, 373.

27. Yvonne, K.; Konrad O.; Volker B.; J. Agric. Food Chem. 2005, 53, 5640.

28. Morales-Delgado, D. Y.; Téllez-Medina, D. I.; Rivero-Ramírez, N. L.; Arellano-Cárdenas, S.; López-Cortez, S.; Hernández-Sánchez, H.; Gutiérrez-López, G.; Cornejo-Mazón, M.; Rev. Mex. Ing. Química 2014, 13, 179.

29. Rein M.; Heinonen, M.; J. Agric. Food Chem. 2004, 52, 3106.

30. Goméz-Linton, D. R.; Navarro-Ocaña, A.; Alavez, S.; Pinzón-López, L.; Trejo-Aguilar, G. M.; Pérez-Flores, L. J.; Rev. Mex. Ing. Química 2020, 19, 1083.

31. Escobedo-González, R.; Cabañas, A. V. V.; González, A. M.; Sánchez, P. M.; Saavedra-Leos, Z.; Cruz-Olivares, J.; Serrano, J. N.; Martínez, J.; Ruvalcaba, R. M.; Molecules 2019, 24, 3035.

32. Romero-Díez, R.; Matos, M.; Rodrigues, L.; Bronze, M. R.; RodríguezRojo, S.; Cocero, M. J.; Matias, A. A.; Food Chem. 2019, 272, 258.

33. Abenoza, M.; Benito, M.; Saldaña, G.; Álvarez, I.; Raso, J.; SánchezGimeno, A. C.; Food Bioprocess Technol. 2012, 6, 1367.

34. Robles-López, M. R.; de la Torre, R. R.; Camarillo-Cadena, M.; Hernández-Arana, A.; Welti-Chanes, J. S. W.-C.; Hernández-Sánchez, H.; Rev. Mex. Ing. Química 2012, 11, 373.

35. Leong, S. Y.; Treadwell, M.; Liu, T.; Hochberg, M.; Sack, M.; Mueller, G.; Sigler, J.; Silcock, P.; Oey, I.; Innov. Food Sci. Emerg. Technol. 2020, $59,102243$.

36. Maza, M. A.; Martínez, J. M.; Delso, C.; Camargo, A.; Raso, J.; Álvarez, I.; Innov. Food Sci. Emerg. Technol. 2020, 60, 102303.

37. Comuzzo, P.; Voce, S.; Grazioli, C.; Tubaro, F.; Marconi, M.; Zanella, G.; Querzè, M.; Foods 2020, 9, 414.

38. Saulis, G.; Food Eng. Rev. 2010, 2, 52.

39. Ricci, A.; Parpinello, G. P.; Versari, A.; Beverages 2018, 4, 18.

40. Odriozola-Serrano, I.; Soliva-Fortuny, R.; Martín-Belloso, O.; LWT Food Sci. Technol. 2009, 42, 93.

41. Aguiló-Aguayo, I.; Soliva-Fortuny, R.; Martín-Belloso, O.; J. Food Eng. 2009, 92, 37.

42. Chen, D.; Zhang, M.; Shrestha, S.; Food Chem. 2007, 103, 1343

43. Andrade-Avila, Y. Y.; Cruz-Olivares, J.; Pérez-Alonso, C.; Ortiz-Estrada, C. H.; Chaparro-Mercado, M. D. C.; J. Chem. 2017, 6471684.

44. Kumar, S. K.; Johnston, K. P.; J. Supercrit. Fluids 1988, 1, 15.

45. Gupta, R. B.; Shim, J.-J.; Solubility in Supercritical Carbon Dioxide, CRC Press: Boca Raton, 2006.

46. Jiao, G.; Kermanshahi pour, A.; LWT 2018, 98, 237.

47. Barba, A. A.; Dalmoro, A.; d'Amore, M.; Lamberti, G.; LWT - Food Sci. Technol. 2015, 64, 149

48. Ribas-Agustí, A.; Martín-Belloso, O.; Soliva-Fortuny, R.; Elez-Martínez, P.; J. Funct. Foods 2019, 59, 206.

49. Kapadia, G. J.; J. Med. Chem. 2001, 44, 1122.

50. Shi, J.; Khatri, M.; Xue, S. J.; Mittal, G. S.; Ma, Y.; Li, D.; Sep. Purif. Technol. 2009, 66, 322 . 